\title{
DETERMINATION OF INITIAL COMMUTATION ANGLE OFFSET OF PERMANENT MAGNET SYNCHRONOUS MACHINE - AN OVERVIEW AND SIMULATION
}

\author{
Viktor ŠLAPÁK*, Karol KYSLAN*, František MEJDR**, František ĎUROVSKÝ* \\ *Dept. of Electrical Engineering and Mechatronics, Faculty of Electrical Engineering and Informatics, Technical University of Košice, \\ Letná 9, 04200 Košice, tel.055/602 3175, e-mail: viktor.slapak@tuke.sk, karol.kyslan@tuke.sk, frantisek.durovsky@tuke.sk \\ ** Institute of Mechatronics and Computer Engineering, Faculty of Mechatronics, Informatics and Interdisciplinary Studies, Technical \\ University of Liberec, Studentska 1402/2, 46117 Liberec, Czech Republic, tel. +420 485353 510, e-mail: frantisek.mejdr@tul.cz
}

\begin{abstract}
Identification of initial commutation angle belongs to the basic routines at the commissioning of industrial drives with permanent magnet synchronous machine. This paper deals with problem of commutation angle offset determination. Two methods are described and simulated in detail. The first method is based on application of a DC voltage and the second one is based on the use of the current controllers. Both methods use rotor movement to reach defined position. Simulation and experimental results are included providing mutual comparison of these methods.
\end{abstract}

Keywords: commutation angle, initial position, permanent magnet synchronous machine

\section{INTRODUCTION}

Permanent magnet synchronous machine (PMSM) is highly dynamic motor with compact dimensions, mostly used in robotic applications or machine tools. There are several common ways to control PMSM; the most common are v/f control in open loop; field oriented control (FOC) and direct torque control (DTC) in closed loop resp. However, FOC is the most popular in applications requiring high dynamics and precision. Before they are being used in a standard operation, industrial PMSM drives must successfully pass the commissioning routines.

During these routines the following parameters are identified and calculated:

- commutation angle (CA) offset,

- machine parameters,

- parameters of the current controllers,

- parameters of the speed controller,

- parameters of the position controller.

$\mathrm{CA}$ is the angle between the vector of stator magnetic flux position and the vector of magnetic flux created by permanent magnets. If the industrial drive is used for the first time, these vectors are arbitrarily (randomly) placed, thus the angle between them is unknown. Identification of CA is crucial for the FOC of PMSM because the value of CA is necessary for the Park transformation [5]- [8]. Furthermore, if the CA is kept close to the 90 degrees (electrically), PMSM provides the maximum torque at given stator current.

This paper deals with the determination of CA using data from position sensor. If absolute position sensor is used and the value of CA is once obtained, the actual motor electrical position is stored into the EEPROM memory as CA offset and for the next operation this value is loaded from memory, so CA is known immediately. If the position sensor does not have absolute tracks, determination of CA has to be repeated every time during commissioning.

There are various methods, how to determine the CA. Some of them are briefly described in [1], [2], [3] or [4]. In this paper, two approaches of CA determination are completely described, modelled in Simulink environment, and experimentally verified. Results of mutual comparison of presented approaches can be found in conclusion.

\section{MATHEMATICAL MODEL OF PMSM}

Mathematical model of PMSM is described in rotor reference frame as (see [6], [9]):

$\frac{\mathrm{d} i_{d}}{\mathrm{~d} t}=-\frac{R}{L_{d}} i_{d}+\frac{p L_{q}}{L_{d}} \omega i_{q}+\frac{1}{L_{d}} u_{d}$

$\frac{\mathrm{d} i_{q}}{\mathrm{~d} t}=-\frac{R}{L_{q}} i_{q}+\frac{p L_{d}}{L_{q}} \omega i_{d}+\frac{1}{L_{q}} u_{q}-\frac{\psi_{P M}}{L_{q}} p \omega$

$T_{e}=\frac{3 p}{2}\left[\psi_{P M} i_{q}+\left(L_{d}-L_{q}\right) i_{d} i_{q}\right]$

$\frac{\mathrm{d} \omega}{\mathrm{d} t}=\frac{1}{J}\left(T_{e}-T_{L}\right)$

$\frac{\mathrm{d} \varphi}{\mathrm{d} t}=\omega$

where $R, L_{d}$ and $L_{q}$ are the per-phase armature resistance and the $d$-axis and $q$-axis inductances, respectively; $\psi_{P M}$ is the permanent-magnet flux, $p$ is the number of pole pairs, $J$ is total moment of inertia, $T_{e}$ and $T_{L}$ are electromagnetic and load torque, respectively; $\omega$ is rotor angular speed, $\varphi$ is rotor angular position and $i_{d}, i_{q}$ are the $d$-axis and $q$-axis component of the stator current, respectively. Considering rotor reference frame, inputs are voltages $u_{d}$ and $u_{q}$ and outputs are currents $i_{d}$ and $i_{q}$, rotor angular speed $\omega$ and rotor position $\varphi$. However, in the real world, the machine is supplied by 3 -phase voltage and phase currents are measured. Therefore, the machine model was coupled with reference frame transformations. 


\section{DESCRIPTION OF METHODS}

Methods, described in this section, are based on rotor movement from an unknown initial position to zero position by applied voltage and during this routine, the value of CA is considered to be zero. Afterwards, CA is a signal obtained from position sensor.

\subsection{Method I - Determination of CA by DC voltage}

The first method is based on application of constant DC link voltage on the machine in such a way, that positive voltage of a DC link is connected to A phase, and negative voltage of DC link is connected to $\mathrm{B}$ and $\mathrm{C}$ phase, as is depicted in Fig. 1. where vector of a stator current is $\vec{I}_{S}$; vector of a rotor flux by permanent magnets is denoted as $\vec{\psi} ; i_{a}, i_{b}$, $i_{c}$ are phase currents, $\alpha \beta$ is stator 2-phase reference frame; $d q$ is rotor reference frame and $\rho$ is value of CA offset.

At the moment of DC voltage application, rotor flux vector is arbitrarily placed, according to actual rotor position Fig. 2(a) Application of DC voltage causes constant current flow in all phases and places stator current vector in $\alpha$-axis. Therefore, rotor is forced to move towards stator flux caused by stator current vector until both flux vectors are aligned, as in Fig. 2(b). Thus, CA is now considered as zero. There is also a possibility to align machine electrical position with $q$-axis by following connection: phase $\mathrm{A}$ is floating, phase $\mathrm{B}$ is connected to positive voltage and phase $\mathrm{C}$ is connected to zero voltage Fig. 3. In this case, electrical position after reference frames alignment is $\rho=\pi / 2$ as rotor flux lies in $\beta$-axis (see Fig. 4(b)). The simulation scheme for this method is in Fig. 8

\subsection{Method II - Determination of CA by using current controller}

The second method uses PI current controllers for $d$ and $q$ current components in closed loop similar to current control loop in FOC. In this case, comparing to previous method, current components are controlled. The difference between normal FOC current loop and this method lies in transformation angle used for current feedback. Here, assumed transformation angle (or CA) remains zero during whole procedure (see simulation scheme in Fig. 97. Desired current $d$-component value is set to reference value (usually motor nominal current value or less) and current $q$-component reference is set to zero. Both references cause that stator current vector is placed to $\alpha$-axis (as transformation angle is held to zero), similarly to Method I. Considering an angle between stator current vector and rotor flux vector is no-zero, rotor starts to move until both vectors are aligned and no torque is produced. At this point, actual position is stored as a commutation offset, current setpoints are set to zero and transformation angle for current feedback is switched from the constant value to measured one.

It is also possible to set desired current $d$-component to zero and $q$-component to the reference value. In this case, stator current vector is placed into $\beta$-axis. After the rotor movement, when stator and rotor flux are aligned, the commutation angle is $\rho=\pi / 2$. In fact, there is no significant difference in using alignment with $\alpha$ or $\beta$-axis that clearly determines the right manner. However, from the practical point of view, current $d$-component is usually held on zero value in FOC motor control, so it is more convenient to maintain this approach.

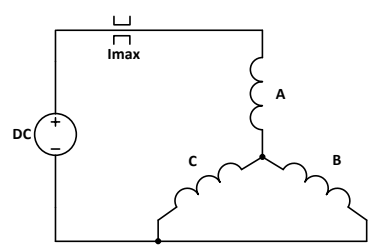

Fig. 1 Aligment with $d$ axis - schematic

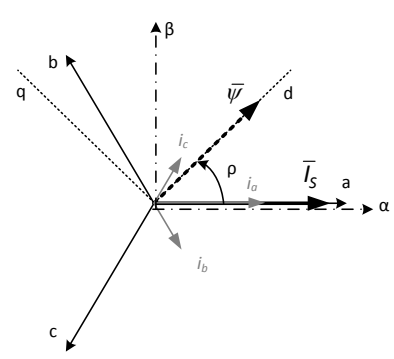

(a) before aligment

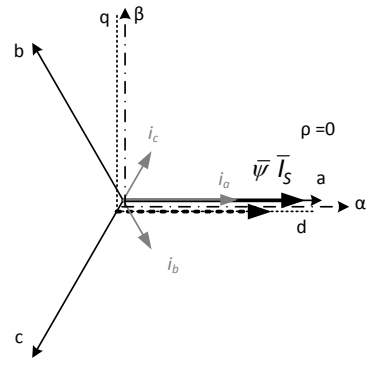

(b) after aligment
Fig. 2 Phase diagrams for aligment with $d$ axis

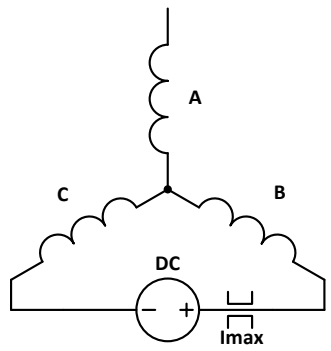

Fig. 3 Aligment with $q$ axis - schematic

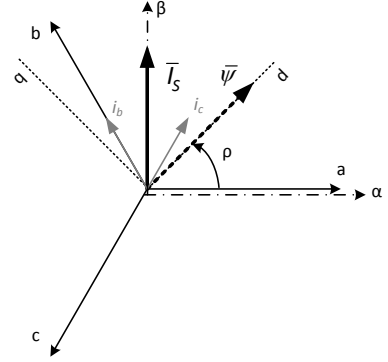

(a) before aligment

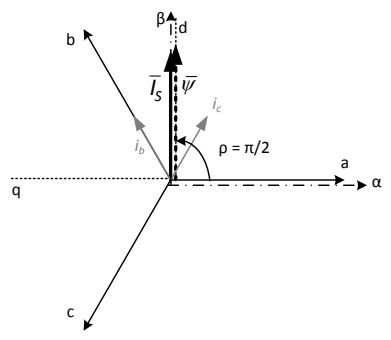

(b) after aligment
Fig. 4 Phase diagrams for aligment with $q$ axis 

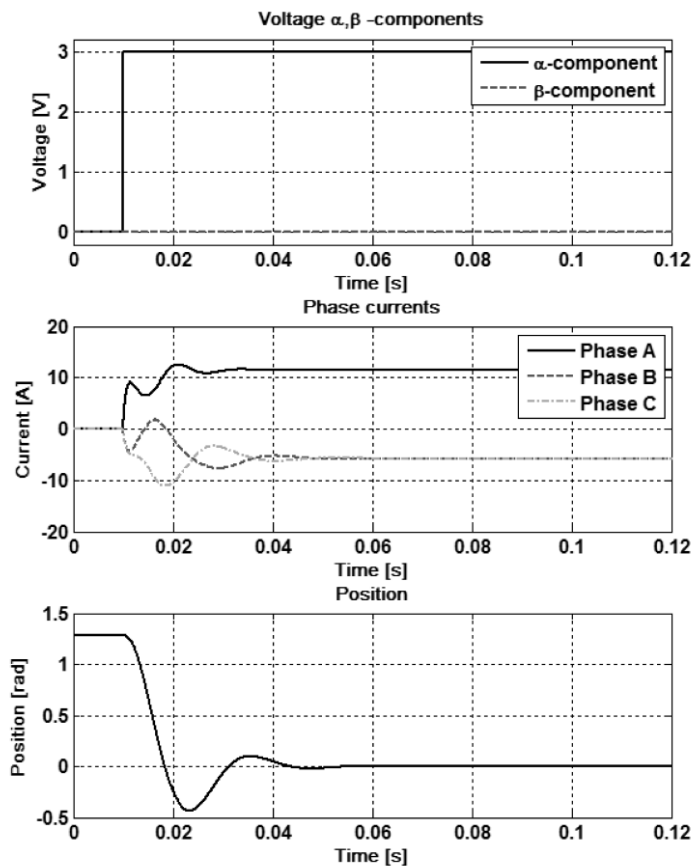

(a) Method I, aligning with $\alpha$-axis
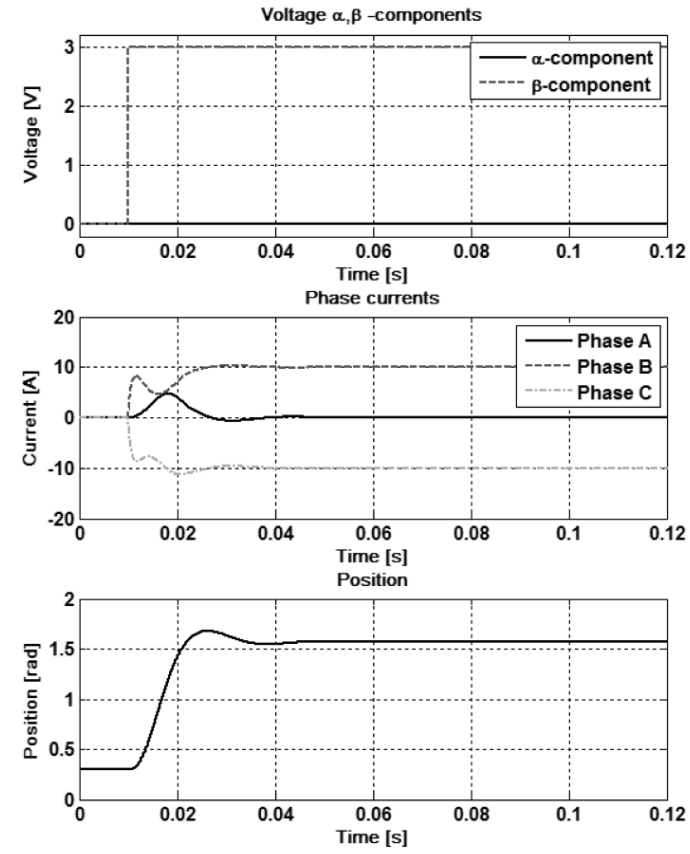

(c) Method I, aligning with $\beta$-axis
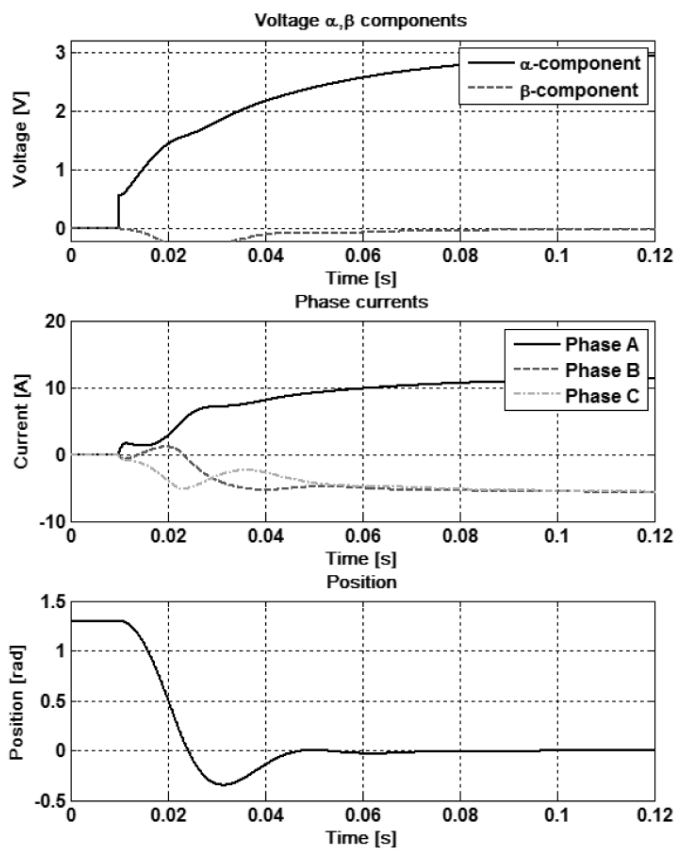

(b) Method II, aligning with $\alpha$-axis
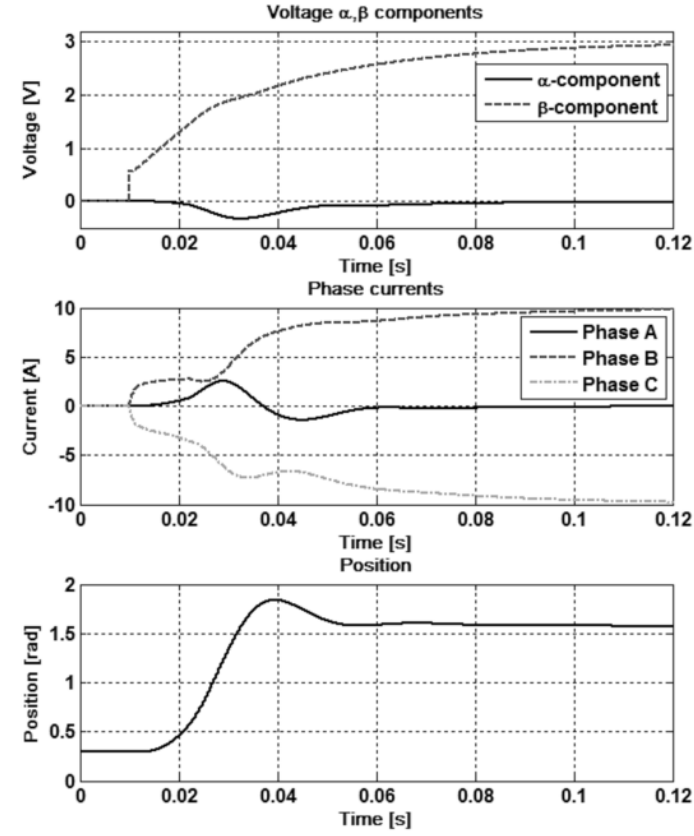

(d) Method II, aligning with $\beta$-axis

Fig. 5 Simulation results for both Method I and Method II

\section{SIMULATION RESULTS}

Both methods were simulated with same motor model in Matlab/SIMULINK. A standard mathematical model of a PMSM machine in $d q$ reference frame is used, as described in Section 2.
It was assumed that PMSM is loaded with static friction during movement, therefore appropriate load torques were applied with Signal builder block. Note that precise simulation of static load torque is a complicated problem beyond the scope of this paper, and so only simplified static load torque value was applied. For this reason, some differences 
between simulation and experimental results occurred.

Simulation results of the Method I is depicted in Fig. 5(a), Value of $1.3 \mathrm{rad}$ was used as a random initial rotor electrical position of PMSM. Voltage vector, that was applied on the machine in the simulation, is placed into $\alpha$ axis (voltage $\beta$-component is zero), thus stator current and flux is in $\alpha$-axis as well. It can be observed, that at the $t=60 \mathrm{~ms}$, when phase currents become constant, rotor is pulled into the zero position. The same simulation conditions were applied also on the simulation of Method II, depicted in Fig. 5(b).

Both described methods were also simulated with voltage applied in $\beta$-axis, simulations results are in Fig. 5(c) for Method I and in Fig. 5(d) for Method II. The same simulation conditions were used, the only difference was in initial position. In this case, initial electrical position was set to $0.3 \mathrm{rad}$. It can be observed, that simulation responses of both methods are similar to responses on voltage applied in $\alpha$-axis. The final rotor position is $\rho=\pi / 2$ and rotor flux is aligned with $\beta$-axis. Response time of Method II is slightly larger in comparison to Method I, but both methods are still fast enough, considering the fact that CA determination runs only once.

\section{APPLICATION ISSUES AND EXPERIMENTAL RESULTS}

Experimental setup in Fig. 6 consists from PMSM fed by voltage source inverter (VSI), controlled by Texas Instruments floating point DSP. Actual position of PMSM is measured by sine/cosine incremental encoder with 2048 lines per revolution and with absolute tracks. Encoder signals are firstly evaluated by electronic interface to obtain suitable signals for DSP. Parameters of PMSM in experimental setup are in Table 1. Method I, based on DC voltage and described in the paper, is frequently used in industrial power converters, and can be easily implemented on DSP. Therefore, it was experimentally verified. Commutation angle given by described method is used in FOC control algorithm and implemented just on the same experimental setup.

It is possible to determine the CA offset with Method I by switching on the corresponding transistors in VSI. But if full DC-link voltage is applied directly on the machine with small value of phase resistance, it leads to very high current and damage of the machine is very likely. In experiments voltage applied on the machine by VSI was modulated with PWM in order to get a permissible value. Thus, maximum allowed motor current have not been exceeded. Reference values for phase voltages are computed as it is in simulation scheme in Fig. 8, i.e. voltage vector is placed on $\alpha$-axis by defining voltage $\alpha$-component, whereas $\beta$-component remains zero and this references are transformed to 3-phase by inverse Clarke transformation. The main algorithm is described by simplified flowchart in Fig. 7 .

Experimental results were compared to the simulation results from Fig. 5(a) and results are in Fig. 10. It can be observed that experimental results correspond with simulation results. Differences are caused by friction and static load torque, which are not concerned in the model.

\section{CONCLUSION}

The paper presents an overview and detailed explanation of two solutions to a practical problem with commutation angle offset determination of PMSM control.

Presented methods are based on rotor movement with limited current. Therefore, they should be solely used without the load on the motor output. Otherwise, results may not be satisfying and possibly lead to undesired behaviour such as inappropriate currents to given load, which causes unwanted increase of machine temperature and impossibility to reach reference torque. Advantage of the Method I is its simplicity and effectiveness. On the other hand, Method II brings controlled currents during procedure, but it is more complicated and needs to switch the feedbacks after CA offset determination.

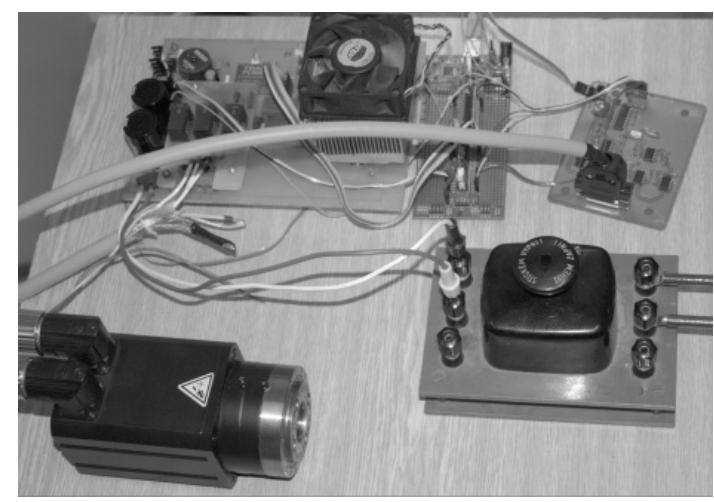

Fig. 6 Experimental setup with VSI and PMSM

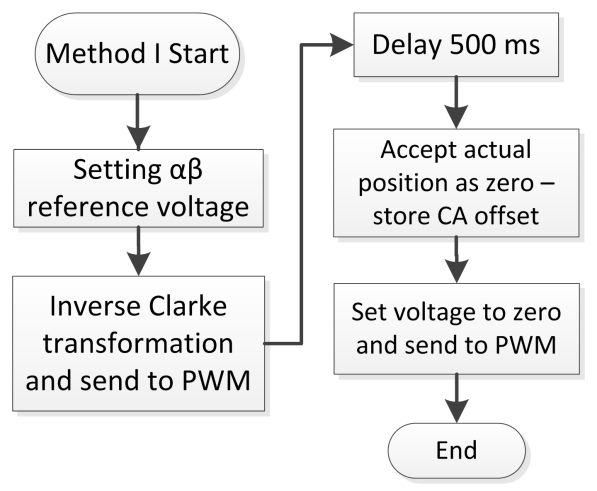

Fig. 7 Main Control Algorithm of FOC

Table 1 PMSM machine parameters

\begin{tabular}{|cl|}
\hline parameter & value \\
\hline$R$ & $0,26 \Omega$ \\
$L_{d}$ & $0,165 \mathrm{mH}$ \\
$L_{q}$ & $0,165 \mathrm{mH}$ \\
$2 p$ & 10 \\
$K_{t}$ & $0,07 \mathrm{Nm} / \mathrm{A}$ \\
$J$ & $0,006 \mathrm{~kg} \cdot \mathrm{m}^{2}$ \\
\hline
\end{tabular}




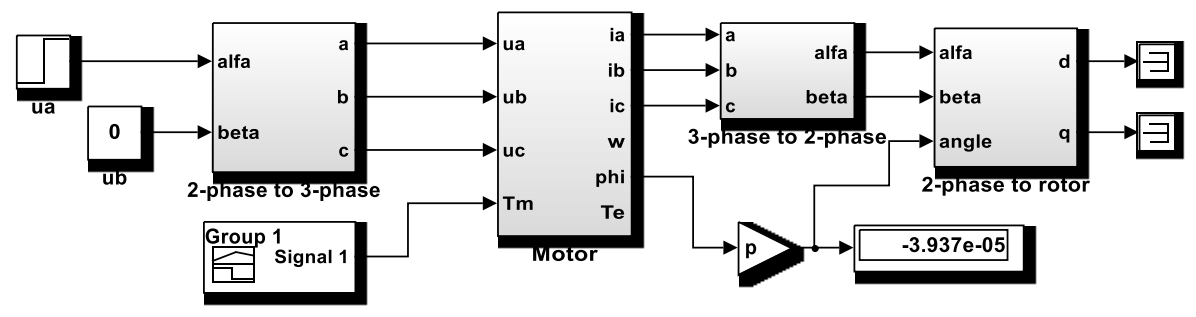

Fig. 8 Simulation Scheme of Method I - Determination of CA by using constant DC voltage

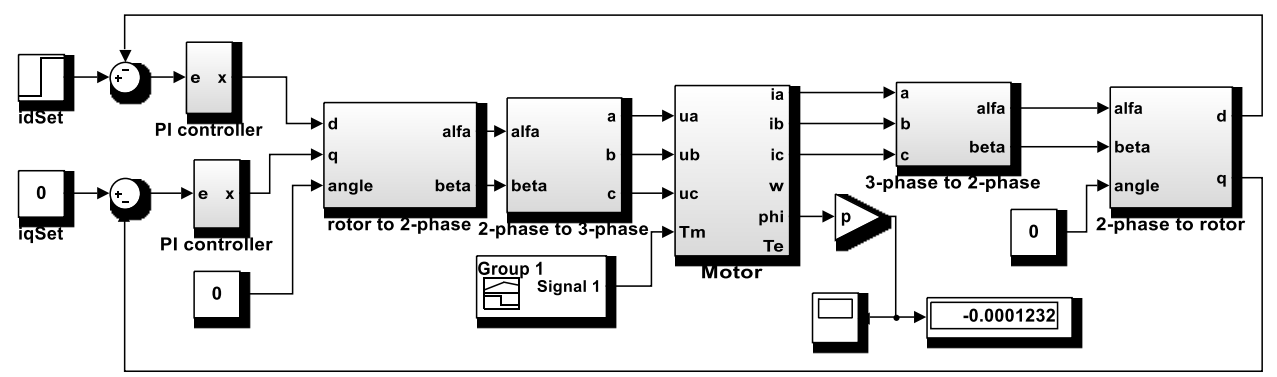

Fig. 9 Simulation Scheme of Method II - Determination of CA by using PI current controllers
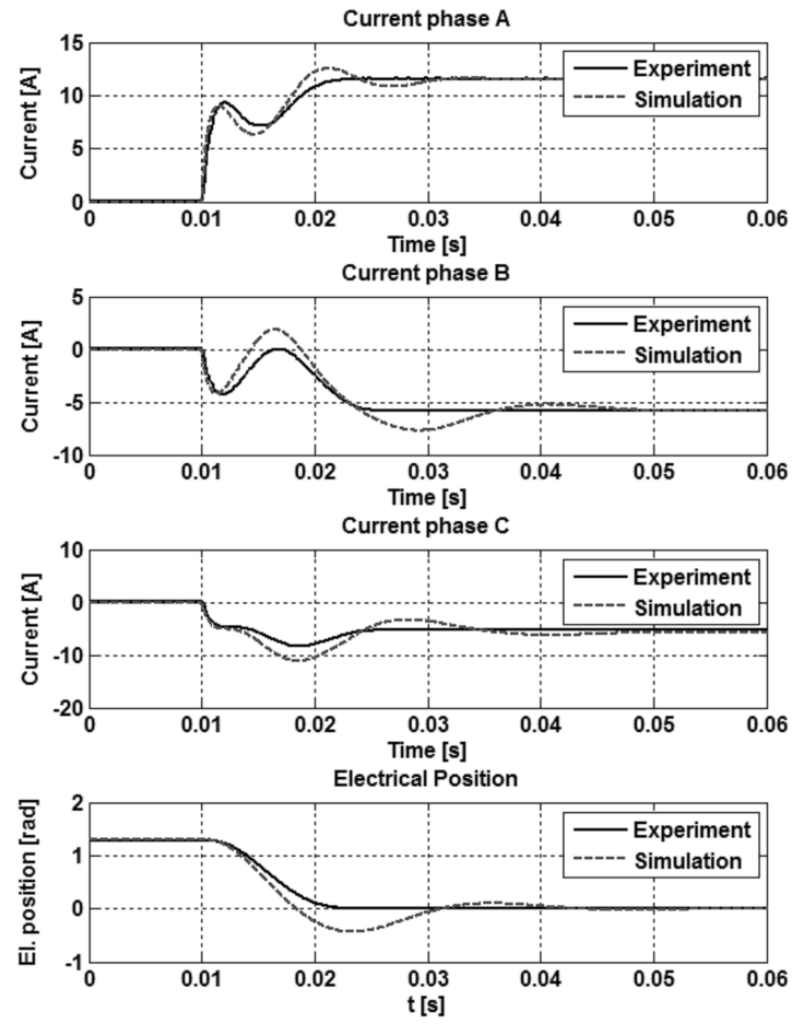

Fig. 10 Experimental verification of Method I

\section{ACKNOWLEDGEMENT}

This work was supported by the Slovak Research and Development Agency under the bilateral project SKCZ-2013-0065. This work was also supported by the Slovak Cultural and Educational Agency of the Ministry of Education of Slovak Republic under the contract KEGA 042TUKE-4/2012 Teaching Innovation in Control of Mechatronic Systems.

\section{REFERENCES}

[1] HIPERFACE, Description of the HIPERFACE Interface, available in 11/2014, WWw.sick.com/group/EN/home/general/portrait/ Pages/std_hiperface.aspx

[2] TEXAS INSTRUMENTS, Implementation of a Speed Field Oriented Control of 3-phase PMSM Motor using TMS320F240, available in 11/2014, www.ti.com/lit/an/spra588/spra588.pdf

[3] MICROCHIP, Sensorless Field Oriented Control (FOC) for Permanent Magnet Synchronous Motors, available in 11/2014,

WWw.microchip.com/stellent/groups/sitecomm_ sg/documents/training_tutorials/en532365.pdf

[4] BOSH REXROTH AG, Rexroth IndraDrive Firmware for Drive Controllers MPH-02, MPB-02, MPD-02, available in 11/2014, 
http://www. boschrexroth.com/country_units/ america/united_states/sub_websites/brus_dcc/ documentation_downloads/ProductDocumentation/ CurrentProducts/Drives/IndraDrive/firmware/ MPx02/MPx-02VRS_FK01.pdf

[5] SCHMIDT, P.B. - GASPERI, M.L. - RAY, C. WIJENAYAKE, A.H.: "'Initial rotor angle detection of a nonsalient pole permanent magnet synchronous machine," IEEE Industry Applications Conference, 1997. IAS '97., vol.1, pp.459,463 vol.1, 5-9 Oct 1997, DOI: 10.1109/IAS.1997.643063

[6] SEUNG-KI SUL: Control of Electric Machine Drive Systems, John Wiley \& Sons, New Yersey, 2011, ISBN 978-0-470-59079-9

[7] BRANDSTETTER, P. - KRECEK, T.: "Sensorless control of permanent magnet synchronous motor using voltage signal injection”. Elektronika Ir Elektrotechnika, vol. 19, no. 6, pp.19-24, 2013, DOI: dx.doi.org/10.5755/j01.eee.19.6.1583

[8] VITTEK, J. - VAVRÚŠ, V. - BRIŠ, P. - GOREL, L.: "Forced Dynamics Control of the Elastic Joint Drive with Single Rotor Position Sensor", Automatika Journal for Control, Measurement, Electronics, Computing and Communications, vol.54, no. 3, pp. 337-347, 2013, DOI 10.7305/automatika.54-3.160

[9] PILLAY, P. - KRISHNAN, R.: "Modelling of permanent magnet motor drives", IEEE Transactions on Industrial Electronics, vol.35, no.4, pp. 357-541, 1988, DOI: $10.1109 / 41.9176$

Received December 8, 2014, accepted January 27, 2015

\section{BIOGRAPHIES}

Viktor Šlapák received M.Sc. degree from the Technical University of Koice, Koice, Slovak Republic, in 2012. $\mathrm{He}$ is currently a PhD. student at Department of Electrical Engineering and Mechatronics, TU Koice. His research interests are advanced control methods of electrical drives and power converters and its implementation on microprocessor units.

Karol Kyslan received M.Sc. and Ph.D. degrees from the Technical University of Koice, Koice, Slovak Republic, in 2009 and 2012, respectively. He is currently an Assistant Professor at the Department of Electrical Engineering and Mechatronics, TU Koice. His research interests are the control of electrical drives, hardware-in-the-loop simulation and rapid control prototyping.

František Mejdr received M.Sc. degree from the Technical University of Liberec, Liberec, Czech Republic, in 2013. He is currently working towards his Ph.D. degree at the Department of Mechatronics and Computer Engineering, TU of Liberec. His interest is in the area of motor control and $\mathrm{CNC}$ technology.

František Ďurovský received M.Sc. and Ph.D. degrees from the Technical University of Koice, Slovak Republic, in 1983 and 1993, respectively. He is currently an Associated Professor at the Department of Electrical Engineering and Mechatronics, TU Koice. His field of research interests are motion control, electrical drives in industrial and automotive applications, control and simulation of mechatronic systems. 